\section{El legado de Maritza Montero a la psico- logía comunitaria}

Jalisco, noviembre 30 de 2016.

\author{
Por: Irineo González Rodríguez \\ Estudiante de Psicología \\ Universidad de Guadalajara \\ Centro Universitario de los Valles \\ Jalisco, México \\ E-mail: irineogr@hotmail.com
}

Apreciada Maritza Montero. Reciba mi respetuoso y cordial saludo. Soy estudiante de tercero de psicología en la Universidad de Guadalajara, México. Me gustaría comentarle que encomio sus diez distinciones, premios y reconocimientos y resalto con gusto el Premio de la Sociedad Interamericana de Psicología en 1995. Admiro sus cuarenta investigaciones, de las cuales me gustaría examinar Análisis crítico de procesos y teoría del fortalecimiento comunitario. Además, me fue interesante darme cuenta de su extendida labor docente nacional e internacional.

Sus fundamentos teóricos de la psicología social comunitaria han influido en una gran cantidad de psicólogos comunitarios del mundo, han aportado orientaciones y precisiones para desarrollar el trabajo y la salud psicosocial comunitaria, y contribuido a la formación de objetivos, aspectos metodológicos y asesoramiento, entre los que sobresale su investigación-acción como base para la transformación. Es de valorar francamente su amplia contribución desde la perspectiva psicológica, a lo epistemológico, lo filosófico, lo histórico, lo ontológico, lo ético, lo científico, lo metodológico, lo profesional y lo político.

Deseo decirle que en la asignatura de "Psicología y Contexto Sociohistórico: Problemática Nacional”, analizamos el capítulo 5 "La comunidad como ámbito de la ciudadanía", de su libro Teoría y práctica de la psicología comunitaria, a partir del cual se elaboró un mapa conceptual por alumno y una exposición en clase presencial, lo que resultó muy enriquecedor. En otra materia, se nos dejó la tarea de escribir un ensayo acerca de un libro de un autor de nuestra elección que incluyera psicología latinoamericana, razón que me hizo pensar en usted y considerar conveniente leer su libro Introducción a la psicología comunitaria. Desarrollo, conceptos y procesos (estoy por terminar el ensayo).

La verdad, no estaba relacionado con la psicología comunitaria, pero gracias a su obra ahora la comprendo. Incluso me sentí impulsado a buscar más información y encontré en la biblioteca virtual de la universidad Psicología Social Comunitaria, texto que pretendo leer en vacaciones.

La felicito por sus logros y su compromiso. Sin lugar a dudas, su obras han dejado una profunda huella en las universidades, en muchos docentes y en alumnos. Por ello, la animo a seguir en su labor especializada sin cansarse a pesar de las dificultades o tristezas.

Usted ha dejado en mí una tarea y quisiera que todos los psicólogos tuvieran este propósito en mente: que alcancemos juntos "la hermandad de los ideales y del esfuerzo por una América posible". Su legado no es solo teórico, pues su huella a quedado en el corazón de la comunidad, de las personas, de mis profesores y en el mío.

Me despido como lo hacemos en México: con la cariñosa expresión "cuídate mucho". 